\title{
ПАТРИОТИЗМ КАК ИНТЕРСУБЪЕКТИВНОЕ ЯВЛЕНИЕ В СОЦИАЛЬНО-ФИЛОСОФСКОМ ДИСКУРСЕ
}

\section{PATRIOTISM AS AN INTERSUBJECTIVE PHENOMENON IN SOCIAL AND PHILOSOPHICAL DISCOURSE}

V. Skopa

Summary: Based on the studied material, the article examines the phenomenon of "patriotism" as an intersubjective phenomenon. The analysis of the concept of patriotism is complicated by the fact that it is often perceived in a negative connotation, despite its positive etymological essence. In the presence of a large number of variations in the interpretation of patriotism, scientists distinguish such approaches to its consideration as ideological; active; legal-positivist. Modern researchers, referring to the concept of patriotism, most often analyze its individual types. These include: territorial, family or clan, ethnic patriotism or state. Patriotism as a component of the definition of the political process and the process of state building takes on various forms, where in the context of political studies such concepts as "cosmopolitanism», "false patriotism», «humanitarianism», «patriotic indifferentism» are often encountered.

Keywords: patriotism, social philosophy, public consciousness, individualism, state.

\author{
Скопа Виталий Александрович \\ Д.и.н., Алтайский государственный \\ педагогический университет (г. Барнаул) \\ sverhtitan@rambler.ru
}

Аннотация: В статье на основе изученного материала рассматривается феномен «патриотизма» как интерсубъективное явление. Анализ понятия патриотизма усложняется тем, что его часто воспринимают в негативной окраске, несмотря на положительную этимологическую сущность. При наличии большого количества вариаций интерпретации патриотизма ученые выделяют такие подходы к его рассмотрению как идеологический; деятельностный; юридико-позитивистский. Современные исследователи, обращаясь к понятию патриотизма, чаще всего анализируют отдельные его виды. К таковым можно отнести: территориальный, семейный или клановый, этнический патриотизм или государственный. Патриотизм как составляющая дефиниция политического процесса и процесса государства строительства приобретает разнообразные формы, где в контексте политических исследований часто встречаются такие понятия как «космополитизм», «лжепатриотизм», «гуманитаризм», «патриотический индифферентизм».

Ключевые слова: патриотизм, социальная философия, общественное сознание, индивидуализм, государство.
$\mathrm{H}$ а современном этапе патриотизму уделяется весьма большое внимание как в теоретическом плане - истолкование сути, так и практико-ориентированном - формирование патриотических начал. Патриотизм - этимологически однозначное понятие. В научном дискурсе он актуализируется благодаря многоаспектности своих проявлений. Социологические и политологические исследования обращают внимание прежде всего на патриотизм как консолидирующий фактор или явление, возникающее в результате конформизма определенного социума [4]. В контексте междисциплинарных подходов сформировалась тенденция к переосмыслению патриотизма не как отдельного явления, а как идеологии или составляющей теории государственного управления. В сфере национальной безопасности, государственного управления и научного осмысления патриотизм выступает как составная часть воспитания, социализации и формирования гражданского общества.

Как в научной среде, так и в управленческой практике фиксируются разные подходы к интерпретации феномена патриотизма, что свидетельствует о сложности и многоплановости его содержания, а также о трансфор- мации отношений в рамках категорий «государство Родина - гражданин». И это далеко не случайно: своими корнями категория «патриотизм» восходит к периоду античности. «Патриот» - в переводе с греческого означает «соотечественник» (патрі́ - «отечество»). Античные мыслители рассматривали патриотизм в качестве особо важной нравственной категории долга, защиты и действенного участия гражданина в жизни государства. На это указывает известное изречение Цицерона: «Самые благородные помышления - о благе Отечества» [11, с. 84]. Уже в понимании древних философов эта категория, наполняясь позитивным социальным содержанием, обретала черты почетного нравственно-политического принципа.

Традиционалистский подход к патриотизму как проявление общественного сознания существует в историко-культурной традиции довольно аргументированно. В условиях информатизации и глобализации общества психологический аспект в трактовке патриотизма приобретает все большую основу в понимании рассматриваемого феномена. Именно эмоциональная окраска способствует как усилению коллективного действия, так и обострению индивидуальных мотивов. 
Историография заявленной проблемы имеет весомую проработку и методологическую глубину. К теме патриотизма обращалась значительная часть мыслителей и ученых со времен античности. Этимологически патриотизм трактуется как «любовь к родине, своему народу, ответственность за судьбу отечества, готовность служить ее интересам; социально-историческое явление, которое в разные эпохи имеет разный социальный смысл» [5].

Исторически, возникновение понятия патриотизма связывают с полисной политикой Древнего Рима и распространением идеалов целостности и неприкосновенности города-государства. В современной научной мысли все чаще распространяется тенденция интерпретации патриотизма в контексте его соотнесенности с национальной идеей. Подтверждением этому - суждение Гала Ариэль «Несмотря на двойственность отношения к патриотизму в политической теории ... стоит согласиться, что сильные патриотические чувства необходимы для национального объединения» [1].

Теоретико-методологический анализ патриотизма проработан в исследованиях Д.Н. Багрецова, Ю.В. Ивченко, А.Н. Малинкина, М. Нуссбаум, А.А. Шаронова. Своеобразным итогом существующих интерпретаций можно отметить выводы М. Сардоса: «С одной стороны, защитники патриотизма в значительной степени не в состоянии артикулировать жизнеспособную концепцию этого явления; ... с другой, нечувствительность критиков или открытое невежество гражданского, нравственного и эпистемологического измерений патриотизма не в состоянии обеспечить окончательные аргументы для его понимания или отрицание ... При таких условиях концепт патриотизма становится частью проблемы, а не решения» [3].

Современные исследования патриотизма осуществляются в сфере управления, психологии, педагогики, социологии и политологии, поэтому вариации интерпретаций разнообразны - от научной категории, к социальному явлению, феномена сознания и социализации. При таких условиях, четкого определения понятия патриотизма трудно проследить. Более того, обращение к нему учеными актуализируется во времена социальных потрясений - войн, социальных революций и борьба за независимость, и обусловлено вызовами как отдельных обществ, так и глобальными изменениями цивилизаций [8].

Современные исследователи, обращаясь к понятию патриотизма, чаще всего анализируют отдельные его виды. К таковым можно отнести: территориальный, семейный или клановый, этнический патриотизм или государственный $[4$, с. $151 ; 6]$. Указанные типологии чаще всего формируются на основе социального фактора, учитывая специфику окружения и воспитания. Однако последние исследования утверждают, что большое значение в формировании патриотического чувства человека имеют индивидуальные мотивы и ценности.

Анализ понятия патриотизма усложняется тем, что его часто воспринимают в негативной окраске, несмотря на положительную этимологическую сущность. Подобная ситуация обусловлена ассоциациями с крайним проявлением патриотизма такими как шовинизм или ксенофобия; глобализационными тенденциями, проявляющимися в обострении космополитизма, а также изменением парадигмы патриота в период мира и войны.

При наличии такого количества вариаций интерпретации патриотизма, ученые выделили конкретные подходы для этого. Так, Шаронов А. предлагает следующую градацию:

- идеологический подход. Патриотизм рассматривается как готовность служить интересам государства, возникает под влиянием конкретных общественных и экономических условий, поэтому и зависит от изменения этих условий;

- деятельностный подход. Патриотизм понимается как мотив общественной деятельности, его главный критерий;

- юридико-позитивистский подход. Патриотизм понимается как государственный патриотизм, главной целью которого является благо и развитие государства [12].

Вместе с тем, следует обратить внимание, что одним из главных критериев в оценке патриотизма является территория - конкретное государство, этнос или общество.

В социальной философии понятие патриотизма исследуется как составляющая общественного сознания и процесса социализации личности. «Патриотическое сознание - часть общественного сознания, представляет собой «выдержку» из всех его частей, касающихся развития и защиты Отечества, и меняется в зависимости от общественной формации» [9].

Патриотизм как составляющая дефиниция политического процесса и процесса государства приобретает разнообразные формы. Так, в контексте политических исследований часто встречаются такие понятия как «космополитизм», «лжепатриотизм», «гуманитаризм», «патриотический индифферентизм». Указанные понятия довольно близки содержательно к понятию патриотизма, хотя и имеют другую эмоциональную и аффективное окраску. Исследования таких явлений обусловлено возрастанием роли политической психологии и маркетинга в контексте политических процессов в современных странах. Оперируя таким сложным феноменом как патриотизм, а именно его эмоциональной окраской, исследователи и практики пытаются спрогнозировать 
возможный результат будущего: от выборов и референдумов до геополитических трансформаций [10]. Таким образом, исходя из этого можно выделить группы понятий, связанных с патриотизмом, имеющих эмоциональную окраску:

Первая группа: патриотический индифферентизм (нейтральность) - бессознательное или неосознанное отношение к стране. Подобное явление может возникнуть по нескольким причинам, среди которых чаще всего выделяют - оккупацию, эмиграцию, потерю исторической родины или родителей.

К нейтральным следует отнести также патриотический нигилизм, а именно гуманитаризм и космополитизм. Гуманитаризм - это «абстрактная любовь ко всему, что имеет «человеческое лицо». Это явление часто встречается в виде «абстрактного гуманизма», «всеобщей любви», «любви к человечеству». Оно не конкретное и не жертвенное, как истинный гуманизм, а лишь выполняет функцию «ширмы». Космополитизм - «явление часто негативное и неоднозначное, это индивидуально-эгоистическое отчуждения от родины и безразличное к ней отношение» [7]. Возникает как результат недовольство родиной, страной, семьей. Для космополита такой эмоции как любовь просто не существует, она атрофирована.

В современных условиях всеобщности и вседоступности, по мнению некоторых исследователей, космополитизм является механизмом адаптации, «возможностью себя познать», ведь «воздух не подчиняется международным границам» [7, с. 116]. Вариантом существования такой «планетарной любви» есть потребность в решении глобальных проблем современного мира инкультурации, экономической, политической, информационной экспансии. Однако, при таких условиях, сам космополит, даже будучи «гражданином мира», остается в одиночестве. Крайним проявлением космополитизма является планетаризм - «наднациональное осознание принадлежности к человечеству Земли, любовь ко всему живому, солидарность с ним, готовность на жертвы ради него» [7]. В политическом контексте планетаризм проявляется как сверхнационализм.

Вторая группа: непатриотизм (отрицание) - «забвение отечества», исчезновение из предметного поля внимания личности [4]; а также антипатриотизм - ненависть к родине, которая возникает как результат разочарования в силу страны, в свои ожидания. К негативным следует также отнести лжепатриотизм - социопатические явление игры на эмоциях окружающих, ради выгоды, а также псевдопатриотизм - «маску» ради получения выгоды. Крайними проявлениями космополитизма, как уже отмечалось выше является сверхнационализм, распространенный в формах интернационализма (К. Маркс, В. Ленин) и национализма. Яркое проявление всеобщей любви и прежде всего преданности идеи в современном мире чаще всего проявляется в форме экстремизма (экономического, политического, религиозного, экологического, молодежного). Начальными этапами в формировании экстремистских убеждений являются те же этапы, что и в процессе формирования патриотических убеждений, а именно:

- формирование влияния негативных и позитивных факторов на этот процесс;

- перемещение ценностей патриотизма в структуру личности через самооценку и самокоррекцию в соответствии с патриотическими ценностями;

- включение личности в патриотическую деятельность, имеет ценностную направленность [1].

Третья группа: положительная ностальгия. Ностальгия возникает в результате миграционных или эмиграционных процессов. Изменив среду, вызывает ощущение враждебности, человек, со временем, начинает отделять условия пребывания от места пребывания. При таких условиях возникает стойкое ощущение потери и незавершенности, невозможности активно участвовать в жизни родины. Именно ностальгия объясняет такой уровень активности среди эмигрантов - диаспоры - их гуманитарную активность и заинтересованность различными общественными проектами, связанными с родиной. Крайними проявлениями ностальгии является утопизм и контрпатриотизм. Утопизм характеризуется преувеличенным восприятием реальной ситуации, ее «украшением», верой только в положительный результат. А вот контрпатриотизм - это «утопическое осознание и любовь к идеальной родине, что провоцирует ревность и ненависть в процессе столкновения с социальной реальностью» [6, с. 53]. Для этого явления характерно неосознанное отделение родины от «тех, кто говорит от ее имени». Ярким примером положительно окрашенных понятий, связанных с патриотизмом, является теопатриотизм и антропопатриотизм, возникающий в пределах христианской интерпретации патриотизма. Так, Йохан Хёйзинга предложил такое обобщенное понимание патриотизма - «это воля сохранить и защитить то, чем владеешь и ценишь» [1, с. 95].

Исторически считается, что в период Средневековья патриотизм не распространялся как идея или ощущение, не пропагандировался, ведь и государство, и общество были теократическими и ориентированными на Бога. Однако, в современных исследованиях по религии и политике часто обращается внимание на то, что религия выполняет консолидирующую функцию и в самой своей сути несет патриотическую идею - только эта идея обращена не на «Земное Царство», а на «Божественное Царство» [2]. По таким условиям патриотизм как чувство четко противопоставляется национализму как отношению.

Социологи же обращают внимание на то, что первич- 
но формируется патриотическое отношение к своей семьи, традициям, обычаям, а на основе этих ценностных ориентиров формируется патриотическое отношение к языку, культуре, народу, государству. Такой подход довольно традиционный для науки, а в марксистской философии даже использовался как механизм формирования общегосударственной идеологии, в которой патриотизм как любовь к родине отождествлялся с патриотизмом любовь к государству.

Вместе с тем, еще теоретики политических наук, такие как Т. Гоббс, Дж. Локк, обращали внимание на то, что в основе патриотизма лежит не только коллективные, архетипные образования, но и индивидуальная переоценка и гуманизм. Именно такой патриотизм, будет учитывать расовую, национально-этническую, религиозную, культурную, классовую, социально-групповую самоидентификацию, полностью отражает индивидуальные особенности и целостность личности. Именно этот контекст и отражает современную трактовку интерсубьктивности патриотизма, который является индивидуальным явлением, отражает общие тенденции и устоявшиеся традиции.

Современные исследователи, обращаясь к вопросу патриотизма, часто имеют дело с тем, что, интерпретируя этот феномен как результат коллективного сознания пытаются найти индивидуальные проявления или же наоборот, интерпретируя его как индивидуальную ценность, которая имеет общественное значение - этологический патриотизм. При таких условиях они теряют целостность исследуемого явления, ведь патриотизм невозможно рассмотреть отдельно от взаимодействия Я - Другой, Мы - Они. При таких условиях патриотизм содержит в себе как «аффективные», так и «этологические» черты [12].

Аффективный патриотизм отражает индивидуальное отношение к определенной проблеме конкретного лица и его последователей, он «переполнен» конкретными эмоциями. Этологический патриотизм носит ярко коллективные окраски, проявляется в индивидуальных действиях и поступках. Благодаря такому типу патриотизма формируется гражданская идентичность, как «сознательный процесс отождествления себя с государственным образованием» [3]. Формированию такой идентичности способствуют принятые на государственном уровне модели и типы поведения, культура, идеалы и нормы. Этому процессу способствует построение целостной системы государственной идеологии. Более того, патриотизм, основанный на свободе и стремлении к свободе, порождает солидарность, доверие, поддержку. Именно поэтому, следует учитывать личностный аспект формирования патриотических настроений у населения, как первичный компонент социальной активности. Исторически известны факты, когда отдельное действие или деятельность провоцировала рост патриотических настроений, но никогда само общество (как феномен, объединения, система) их порождало. Стоит также учитывать, что именно индивидуальный патриотизм способен породить интеллектуальный, эмоционально окрашенный продукт, что становится рычагом, стимулом к действию.

Таким образом, можно отметить, что единого подхода к определению сущности патриотизма нет. Более того, довольно ошибочным является односторонний подход к интерпретации этого явление - как субъективного или объективного, индивидуального или общего, социального. В данном случае рациональнее использовать интерсубъективний подход, который позволяет определить сущность и функциональность патриотизма как единство множественного и единичного, социального и индивидуального - более того, индивидуального в общем, и внешнего социального во внутренне личностном. Учитывая все особенности образования и формирования патриотизма, его культурно-историческую, национальную, эмоциональную и социально-политическую составляющую, можно сформировать целостную модель не только социального восприятия, но и трансляцию патриотизма на будущее поколение. Психологический компонент в патриотизме раскрывает возможность к построению комплексной модели явления и является интерсубъективним по своей природе, лежащий в поле единства общего и частного, а не их противопоставлення.

\section{ЛИТЕРАТУРА}

1. Ariely Gal. Evaluations of patriotism across countries, groups, and policy domains. Journal of Ethnic and Migration Studies. 2017. doi: 10.1080 / 1369183Х.2017.1319761

2. Магнитов С. Патриотизм как идеология // Литературная Россия. 2016. № 6.

3. Багрецов Д.Н., Ширшов В.Д. Патриотизм: современные вызовы и перспективы // Педагогическое образование в России. 2016. № 5. С. 63-70.

4. Ивченко Ю.В. Сущность патриотизма: история и современность. Научный вестник Херсонского государственного университета. 2015. Выпуск 6. Том 3. C. 150-153.

5. Малинкин А.Н. Понятие патриотизма: эссе по социологии знания // Социологический журнал. 1999. № 1/2. С. 27-59.

6. Наливайченко И.В. Патриотизм в современной России: изменение содержания и трудности формирования // Гуманитарные и социально-экономические науки. 2011. № 1. С. 23-26.

7. Нуссбаум М. Патриотизм и космополитизмом // Логос. 2006. № 2 (53). С. 110-119. 
8. 0 государственной программе «Патриотическое воспитание граждан Российской Федерации на 2016-2020 годы» постановление Правительства РФ от 30.12.2015 № 1493 (ред. от 13.10.2017). URL: http: //www. consultant.ru/document/cons_doc_LAW_192149/ (Дата 0бращения: 20.06.2021).

9. Слободяник Н. Патриотизм в становлении и развитии личности юноши: экспериментальное исследование // Актуальные проблемы психологии. 2015 Т. 7. Вып. 39. С. 359-368.

10. Хаустов В.М. Патриотизм и патриотическое воспитание // Социально-гуманитарные знания. 2007. № 4. С. 325-331.

11. Цицерон Диалоги «0 государстве», «0 законах»/ М., 1966. 161 с.

12. Шаронов А.А. Анализ взглядов на понятия «патриотизм» и «активность» / А.А. Шаронов // Мир науки: интернет-журнал. 2016. Т. 4. С. 1-10.

(c) Скопа Виталий Александрович (sverhtitan@rambler.ru).

Журнал «Современная наука: актуальные проблемы теории и практики»

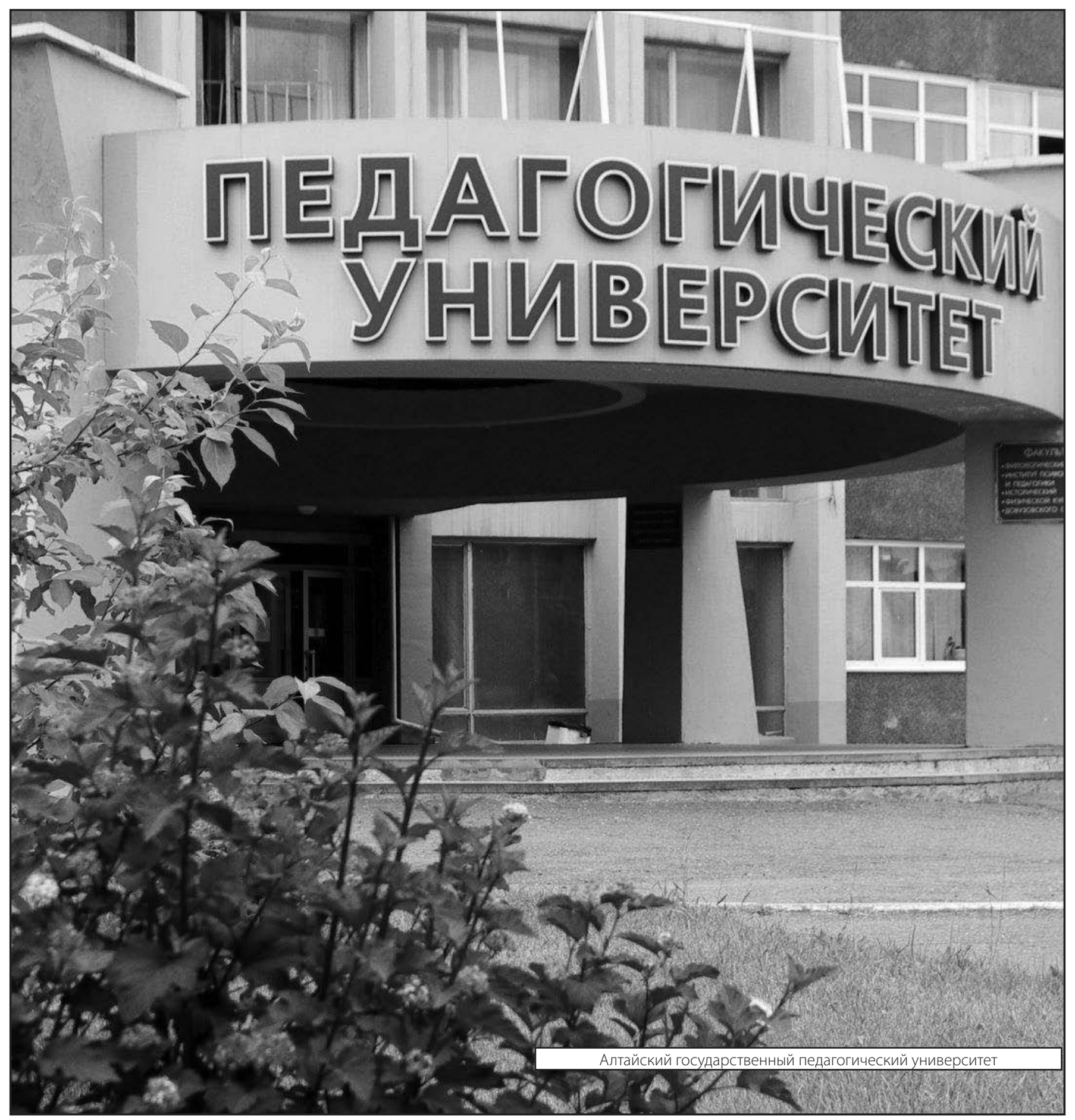

